further work renders this contribution something of an aperitif after the meal. Likewise, Poole's "Introduction to the Phylogeny of Calcified Tissues" has been dealt with by other authors (including Poole himself) in greater depth elsewhere. The impression is given that it was a précis of the major papers of Orvig and Poole published in 1967.

Papers 12, 13, 14, 15 and 16 seem to have little significant contribution to make. Hershkovitz's attempt at a new dental morphological terminology is valiant but by its very nature doomed. Something must be done sometime, but yet another plethora of cumbersome terms simply perpetuates the appalling reputation that dental "cuspologists" or "cristalogists" have acquired for themselves.

Tonge's review on the role of the mesenchyme in tooth development is welcome and Elwyn Simon's on Oligocene and Miocene Old World Anthropoidae is valuable.

Yes, there are a few good things in this volume and they could have been wholeheartedly welcomed a few years ago.

But even if this volume had appeared as long ago as 1969 , it would most probably have received some not overenthusiastic reviews. The blurb and the introduction read splendidly and are most impressive. The actual contents, in contrast, are a disappointment. This volume is a scrapbook of bits and pieces of varying quality. There is no real link even within the separate sections. Take "Phylogeny" for instance; Turnbull and Clemens have related contributions, the rest bear no relation to each other and precious little to phylogeny. In the final part "Morphology", Dahlberg has contributed an article which discusses the "elusive aspects of dental traits in respect to their penetrance and expressivity"-an apt summary of this volume.

L. B. Halstead

\section{Study of a Scavenger}

The Spotted Hyena: a Study of Predation and Social Behaviour. By Hans Kruuk. Pp. xvi +335 . (University of Chicago: Chicago and London, 1972.) $£ 6.75$.

BeCAUSE they compete with man, many carnivores are unpopular, the ungainly spotted hyena occupying pride of place as the most despised of all-at least in popular imagination. Even in some recently published general works the picture of a ghastly cowardly scavenger persists. There might seem to be very little to be said in favour of the spotted hyena.

Hans Kruuk, who studied this animal as part of a wider programme of research initiated by the Serengeti Research Institute in Tanzania, has shown how misleading this proverbial image really is. His book is an account of a carefully planned and thoroughly executed research project which will appeal not only to carnivore enthusiasts but also to those concerned with the broader aspects of mammalian ecology; to the palaeontologist; even to the sociologist.

Kruuk left few avenues of investigation unexplored. He observed hyenas by aeroplane and he followed them on the ground both by day and by night. He fired immobilizing drugs and marked representative animals for subsequent re-identification; and he examined their teeth while they were drugged. $\mathrm{He}$ fitted a radio transmitter to one hyena and kept it under continuous observation for twelve days; and he studied where the hyenas lived, in one lair becoming covered with fleas in consequence. He studied the relationships of hyenas to one another, to other carnivores and to their prey. He estimated the prevalence of sick prey animals and examined hyena droppings to find out what had been eaten. His wife also took part in the studies, fostering a baby hyena which used the Kruuk house as its den.

The story which emerges-packs of hyenas chasing and killing zebra and wildebeest; lions scavenging from hyenas; and lionesses chased up trees by hyenas-contrasts sharply with established ideas. Perhaps the most important observation is the great adaptability which the spotted hyena is shown to have in relation to its environment. Kruuk found that in the Serengeti National Park hyenas travel great distances in order to keep up with migrating wildebeest with consequent high mortality among cubs left unattended by their mothers. The hyenas in the nearby Ngorongoro caldera, however, were found to be an enclosed sedentary population divided into eight "clans" with clearly defined territories and with lower cub mortality. In contrast to the hunting hyenas of these two areas the hyenas living around the walled town of Harar in Ethiopia have become adapted to a scavenging, almost symbiotic, coexistence with man.

This great adaptability which Kruuk has demonstrated is of far reaching significance. In addition to its more obvious application to animal management in Africa today it opens a new field of study for the palaeontologist with evidence already before him that the spotted hyena once spread to Yorkshire and Ireland, with such varied diet as the interglacial hippopotamus and the woolly mammoth and migratory reindeer of cooler times.

The book is well laid out with clear headings, a good index and a valuable bibliography. There is only one cause for regret. The publishers have bound all the half-tone illustrations together as one signature and have not done full justice to the author's brilliant photographs.

This is a remarkable and important book which will attract a diverse readership.

A. J. SUTCLIFFE

\section{Purpose in Behaviour}

Purposive Explanation in Psychology. By M. Boden. Pp. ix +408 . (Harvard University: Cambridge, Massachusetts ; Oxford University: London, August 1972.) $£ 6.50$.

THERE has always been a rift in psychology between those who insist that human behaviour can be understood only in purposive terms and those who refuse to acknowledge any but causalmechanical explanations as scientifically admissible. This book is an attempt to heal that rift by showing us that we can continue in good conscience to be teleologists about human beings, indeed we can scarcely avoid doing so, yet, at the same time, we can recognize that we are physical mechanisms and that ultimately all psychological phenomena are caused by brain processes. The author introduces a valuable distinction here between "strict reducibility" which would imply that all the concepts which appear in the one language must be translatable into those belonging to the other language, so that the former is, in the last resort, redundant, and "empirical reducibility" which requires only the possibility of there being bridging laws which put the two in correspondence. It is this latter benign kind of reductionism which, according to the author, obtains between psychology and physiology. Much of her book is devoted to a detailed examination of the psychology of William McDougall who, though not much read these days, remains historically the arch-spokesman of the teleological approach in psychology. She defends her thesis by showing that, con. trary to what McDougall himself believed, his approach was not incom. patible with an empirical reductionism. She supports this by appealing at length to the new science of artificial intelligence where the same dichotomy reappears as between the purposive aspects of the programming and the deterministic aspects of its physical embodiment in an electronic machine.

The book is a powerfully argued and welcome contribution to the growing body of literature of recent years dealing with the philosophical foundations of psychology. However, the author's treatment of the mind-body problem which was so central for McDougall is, I think, marred by certain philosophical preconceptions which prevent her from doing justice to the dualistinteractionist position. JOHN BELOFF 